\title{
Mismatch Amplification Mutation Assay (MAMA): Application to the c-H-ras Gene
}

\author{
Rita S. Cha, Helmut Zarbl, Phouthone Keohavong, ${ }^{1}$ and William G. Thilly \\ Center for Environmental Health Sciences and Division of Toxicology, Whitaker College of Health Science and Technology, \\ Massachusetts Institute of Technology Cambridge, MA 02139; ${ }^{1}$ Department of Environmental and Occupational Health, \\ Graduate School of Public Health, University of Pittsburgh, Pittsburgh, PA 15261
}

\begin{abstract}
We have found that under appropriate conditions, an allele-specific polymerase chain reaction (PCR) can achieve a sensitivity suitable for measuring specific, infrequent mutations in single cell systems or in animal tissues. Using the 12th codon GC-to-AT mutation in the rat C-Ha-ras gene as a model system, we have defined conditions that allow for measurement of mutations present at frequencies as low as one in $10^{5}$ gene copies. Our approach involved the use of PCR primers that created a single mismatch with the mutated allele (GAA) but created a double mismatch with the wild-type allele (CGA). Five out of the six such double-mismatch primers we tested permitted amplification of the mutant allele (GAA) with a high degree of specificity. The specificity of the assay was further enhanced by using a two-step PCR cycle consisting of a denaturation step (1 min incubation at $94^{\circ} \mathrm{C}$ ) and an annealing/extension step (1 min incubation at $50^{\circ} \mathrm{C}$ ) in the presence of $10 \%$ (vol/vol) glycerol. Reconstruction experiments using genomic DNA demonstrate that this procedure can measure the presence of $\mathbf{3 0}$ copies of the transforming ras allele present amongst $3 \times 10^{6}$ copies of the wildtype allele.
\end{abstract}

A of the polymerase chain reaction that permits specific amplification of sequences differing by as little as a single base pair. ${ }^{(1-5)}$. The technique utilizes primers with specific mismatches at or near the $3^{\prime}$ end to permit preferential amplification of one allele relative to another. Allele-specific PCR offers several advantages over other molecular techniques, such as restriction fragment length polymorphism (RFLP) ${ }^{(6)}$ or differential oligonucleotide hybridization, ${ }^{(7)}$ that are routinely used for measuring known point mutations. The technique is rapid and simple and can readily be applied to analyze nanogram quantities of genomic DNA. ${ }^{(8,9)}$ However, one drawback of the currently available allele-specific PCR protocols is their lack of sensitivity. For instance, whereas RFLP in combination with PCR can detect a point mutation in genomic DNA samples occurring at a frequency of 1 in 10,000 or less, ${ }^{(10,11)}$ the previous estimate of the sensitivity of the allele-specific PCR (determined by ethidium bromide staining) was about 1 in $40 .^{(8)}$ This low sensitivity is due to the fact that primers with mismatches at or near the 3 ' end are still able to extend to some degree under most PCR conditions. Kwok et al. ${ }^{(12)}$ estimated the efficiency of a single-base mismatch primer extension to be between $15 \%$ and $50 \%$ per cycle of the efficiency for a perfect match primer extension, depending on the nature of mismatches.

The sensitivity of mutation assays is not critical when analyzing a relatively homogeneous population of cells where a mutation is shared by a significant fraction of the population. However, the study of a heterogeneous cell population where only a small fraction of the cells $\left(\leqslant 10^{-4}\right)$ are expected to contain a mutation necessitates the use of an assay with a high level of sensitivity. In our attempt to improve the sensitivity of the technique, we optimized the procedure by varying (1) the number and kinds of mismatches in the primers, (2) the temperature and duration of the primer annealing and extension step, and (3) the solvent condition of the reaction mixture. As an example, we utilized one of the transforming alleles of rat c-H-ras gene (G-to-A transition at the 12th codon) as the specific sequence to be amplified. In this paper, we describe the modified allele-specific PCR protocol, which we have designated as the mismatch amplification mutation assay (MAMA), and we demonstrate that the technique is sensitive enough to detect 30 copies of the transforming allele present amongst $3 \times 10^{6}$ copies of wildtype allele.

\section{MATERIALS AND METHODS}

\section{Development of MAMA}

Development of this protocol involved four variables: (1) mismatch primer sequence, (2) temperature of primer extension, (3) time permitted for extension, and (4) concentration of glycerol. We tested and optimized each of these variables as described below.

\section{Mismatch Primers}

Because a single G-to-A transition was to be assayed, we created a series of primers that contained an $\mathrm{A}$ in the appropriate position and varied the base $3^{\prime}$ or $5^{\prime}$ to 
this position. This series of six potentially useful double-mismatch primers contained one mismatch within the 3 'CTT-5' sequence of the mutated allele but two mismatches with the $3^{\prime}-$ CCT-5' sequence of the wild-type allele (Table $1)$. To test the report that a single $3^{\prime}$ ultimate or penultimate mismatch would not yield a preferential amplification, ${ }^{(1,12)}$ two primers with these single mismatch configurations (PA and PA-1) were also prepared, as were the two primers carrying triple mismatches to the wild-type sequence (Table 1). All the primers tested are 20 nucleotides long and synthesized by Research Genetics (Huntsville, AL).

\section{Temperature and Duration of Primer Extension}

Instead of using a standard three-step PCR cycle consisting of a denaturation step, a primer annealing step, and an extension step, ${ }^{(13,14)}$ we tested two-step PCR cycles consisting of a denaturation step and a primer annealing/extension step. The first step was kept constant at $94^{\circ} \mathrm{C}$ for $1 \mathrm{~min}$, while the second step was varied. Temperature was varied be- tween $48^{\circ} \mathrm{C}$ and $57^{\circ} \mathrm{C}$, and the extension was permitted to proceed for either 1 min or $5 \mathrm{sec}$.

\section{Concentration of Glycerol}

To test whether solvent condition would affect the specificity of allele-specific amplification, we modified the PCR reaction mixture by an addition of either $5 \%$ or $10 \%(\mathrm{vol} / \mathrm{vol})$ glycerol.

\section{DNA Preparation}

Wild-type genomic DNA was obtained

TABLE 1 The Mismatch Primers Tested for Allele-specific Amplification

\begin{tabular}{|c|c|c|c|c|c|}
\hline \multirow{2}{*}{ wild type 17} & 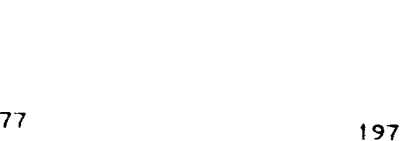 & \multicolumn{2}{|c|}{$\begin{array}{l}\text { B. 5'- GCT GGA -3' } \\
\text { 3'- CGA CCT -5 }\end{array}$} & \multicolumn{2}{|c|}{$\begin{array}{c}\text { Transforming allele } \\
\text { 5'- GCT GAA -3' } \\
\text { 3'- CGA CTT -5' }\end{array}$} \\
\hline & CTTGTGGIGGTGGGC GCT GGA & Mismatches & $\underline{Y}_{o(w t)}{ }^{\star \star}$ & Mismatches & $\underline{Y}_{o(t)}{ }^{\star *}$ \\
\hline PA & & $\begin{array}{l}5^{\prime} \text { - CTGA - 3' } \\
3^{\prime} \text { - GACE्CT -5' }\end{array}$ & 0.70 & $\begin{array}{l}5^{\prime}-\text { CTGA -3' } \\
\text { 3'- GACT -5' }\end{array}$ & 0.70 \\
\hline PA-1* & & 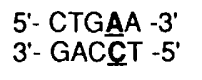 & 0.70 & $\begin{array}{l}\text { 5'- CTGAA -3' } \\
\text { 3'- GACT -5' }\end{array}$ & 0.70 \\
\hline PAA $-1^{*}$ & & $\begin{array}{l}\text { 5'- CTAAA }-3^{\prime} \\
3^{\prime} \text { - GACCT }-5\end{array}$ & $<0.007^{\#}$ & $\begin{array}{l}\text { 5'- CTAAA -3' } \\
\text { 3'- GACETT -5' }\end{array}$ & 0.70 \\
\hline PAA & & $\begin{array}{l}\text { 5'-CTAA }-3^{\prime} \\
3^{\prime}-\text { GACCT - } 5^{\prime}\end{array}$ & $\leq 0.0002^{\# \#}$ & $\begin{array}{l}\text { 5'- CTAA }-3^{\prime} \\
\text { 3'- GACETT -5' }\end{array}$ & 0.70 \\
\hline PCA & & $\begin{array}{l}5^{\prime}-\mathrm{CTCA}^{-3^{\prime}} \\
3^{\prime}-\mathrm{GACC} T-5^{\prime}\end{array}$ & $<0.007$ & $\begin{array}{l}\text { 5'- CTCA } \\
3^{\prime}-3^{\prime} \\
\text { GAC TT -5' }\end{array}$ & 0.70 \\
\hline PIA & & $\begin{array}{l}5^{\prime}-\text { CTTA } \\
3^{\prime}-3^{\prime} \\
\text { GACCT }-5^{\prime}\end{array}$ & $<0.007$ & $\begin{array}{l}\text { 5'- CTTA } \\
\text { 3'- GACTT }^{\prime} \text { - }^{\prime}\end{array}$ & 0.70 \\
\hline $\mathrm{PGAC}^{*}$ & & $\begin{array}{l}5^{\prime}-\text { CTGAC }-3^{\prime} \\
3^{\prime}-\text { GAC } \underline{C T}-5^{\prime}\end{array}$ & $<0.007$ & $\begin{array}{l}\text { 5'- CTGAC - } \\
3^{\prime} \text { - GACTI - }\end{array}$ & 0.70 \\
\hline PGAI $^{*}$ & & $\begin{array}{l}5^{\prime}-\text { CTGAT }-3^{\prime} \\
3^{\prime}-\text { GACET }-5^{\prime}\end{array}$ & $<0.007$ & $\begin{array}{l}\text { 5'- CTGAI -3' } \\
\text { 3'- GACTI -5' }\end{array}$ & 0.70 \\
\hline PGAG * & —AG & $\begin{array}{l}\text { 5'- CTGAG -3' } \\
\text { 3'- GACET- } 5^{\prime}\end{array}$ & 0.70 & $\begin{array}{l}\text { 5'- CTGAG -3' } \\
\text { 3'- GACTI -5' }\end{array}$ & 0.70 \\
\hline PCAA & -CAA & $\begin{array}{l}5^{\prime}-\text { CCAA } \\
3^{\prime}-3^{\prime} \\
\text { GCC } T \\
-5^{\prime}\end{array}$ & $<0.007$ & $\begin{array}{l}\text { 5'- CCAA - } 3^{\prime} \\
\text { 3'- GACTT -5' }\end{array}$ & $<0.007$ \\
\hline PG-AA & G-AA & $\begin{array}{l}5^{\prime}-\underline{G} T A A-3^{\prime} \\
3^{\prime}-\underline{G} A \underline{C C} T-5^{\prime}\end{array}$ & $<0.007$ & $\begin{array}{ll}5^{\prime}-\text { GTAA } & -3^{\prime} \\
3^{\prime}-\underline{G} A \underline{\mathbf{G}} T T & -5^{\prime}\end{array}$ & 0.58 \\
\hline
\end{tabular}

A. The solid line represents the nucleotides that are identical to the wild-type allele. All of the mismatch primers tested carry an A at position 196 and are 20 nucleotides long, encompassing regions between positions 177 and 196 or 178 and 197 (denoted by *).

B. The nature and the position of mismatches within the wild-type allele and the transforming allele. Mispaired bases are denoted by underlined bold letters.

${ }^{\star \star} Y_{0}$ is the estimated efficiency of the mismatch extension during the first cycle of PCR (see Materials and Methods). The numbers are calculated based on the amount of specific PCR products generated following 30 cycles of PCR under the conditions specified in Figs. 2 and 3.

\#The value $<0.007$ was calculated based on the observation that there was no detectable amplification product $\left(10^{10}\right.$ copies of 74 -bp fragment) following 30 cycles of PCR from $3 \times 10^{5}$ copies of template DNA. The calculated value for $Y_{0}$ using the equation $Y_{0}(1+Y)^{n-1}=$ fold amplification is 0.007 , indicating that under the conditions tested, less than 2100 molecules of the primers were extended from $3 \times 10^{5}$ copies of template DNA during the first cycle.

\#\#The value 0.0002 was calculated based on the observation that approximately $10^{12}$ copies of 74-bp fragment were generated from $3 \times 10^{5}$ copies of wild-type DNA following 45 cycles of PCR under the conditions specified in Fig. 2 (with the assumption that PCR was at the exponential phase of DNA synthesis throughout the 45 cycles; see Results). 
from Fischer 344 rat liver by phenol/ chloroform extractions. ${ }^{(15)}$ The source of the transforming allele of $\mathrm{c}-\mathrm{H}$-ras gene was a rat mammary tumor induced by nitrosomethylurea (NMU, Sigma). The nature of alteration (G-to-A transition at the 12 th codon) was identified by denaturing gradient gel electrophoresis (DGGE) $^{(16,17)}$ and confirmed by Sanger sequencing (data not shown). DGGE analysis indicated that $25 \%$ of the genomic DNA isolated from tumor tissue was the mutated ras allele. Tumor tissue was comprised of about $50 \%$ cancerous cells, with the rest of the tissue being comprised of normal stromal cells which surrounded the malignant cells (histological analysis by Dr. Robert Cardiff, pers. comm.). Thus, a mutant fraction of $25 \%$ indicated that one allele of the c-Ha-ras gene was mutated in the cancerous cells. The quantity and purity of DNA were determined by spectrophotometric measurement. ${ }^{(15)}$

\section{PCR Procedures}

For each PCR reaction, $1 \mu \mathrm{g}$ (approximately $3 \times 10^{5}$ copies of ras gene; see ref. 18) of genomic DNA was mixed with 300 nM each of P2 and P1 or one of the test primers, $37 \mu \mathrm{M}$ of each 2 '-deoxynucleoside 5'-triphosphates (dNTPs, Pharmacia), and $1 \mu l$ of $\left[\alpha^{-32}\right.$ P]ATP $(3000 \mathrm{ci} /$ mmole, New England Nuclear) in $100 \mu \mathrm{l}$ of PCR buffer (10 mM Tris- $\mathrm{HCl}$, pH 8.4, $50 \mathrm{~mm} \mathrm{KCl}, 2.25 \mathrm{~mm} \mathrm{MgCl}_{2}$ ). Approximately 1.7 units of Taq polymerase (Perkin-Elmer Cetus) were added and the mixture was subjected to a number of different PCR conditions as described in the figure legends.

\section{Efficiency}

The efficiency of amplification during the exponential phase of DNA synthesis was estimated by analyzing a $10-\mu \mathrm{l}$ aliquot of the reaction mixture on a $7 \%$ polyacrylamide gel (acrylamide/bis-acrylamide $=38 / 2$ ). The PCR products of the correct size were visualized and quantitated under ultraviolet light following ethidium bromide staining by comparing them to the molecular size standard. For the perfect match primers and one mismatch primer, the efficiencies of amplification were estimated according to the equation $(1+Y)^{n}=$ fold amplification, where $Y$ is the efficiency per cycle during the exponential phase of DNA synthesis and $n$ is the number of cycles. ${ }^{(18)}$ For the primers carrying two or more mismatches, we estimated the efficiency of mismatch extension during the first cycle of PCR $\left(Y_{0}\right)$ using the equation, $Y_{\mathrm{o}}(1+Y)^{n-1}=$ fold amplification, where $Y$ is the efficiency of perfect match extension. Since any extension from mismatch primers carries the sequence of the primer (confirmed by sequencing, data not shown), they are the perfect match templates during subsequent cycles of PCR. The equation assumes that the number of templates extended during the first cycle would be amplified at the same efficiency as the perfect match primers during cycles to follow.

\section{RESULTS}

\section{Specificity of the Allele-specific Primers}

The transforming allele of rat c-H-ras gene used in the current study differs from the wild-type allele by a single nucleotide substitution at the second nucleotide of the 12th codon (Fig. 1 and Table 1). Since the allele to be amplified (the transforming allele) carries an $\mathrm{A}$ instead of a $G$ at the second nucloetide of the 12th codon, all the allele-specific primers were designed to carry an $\mathrm{A}$ at

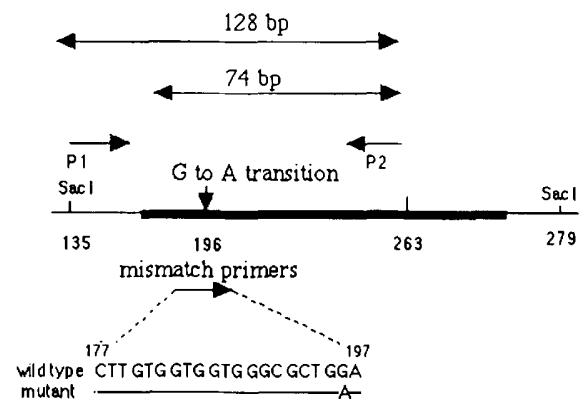

FICURE 1 Structure of rat c-H-ras exon 1 and the primers used for PCR. The solid bar represents the coding region of $\mathrm{c}-\mathrm{H}$-ras exon 1 . The transforming allele has a G-to-A transition at the second nucleotide of the 12th codon (position 196). Primer P1 is a distal primer that does not have any mismatches, and is used as a control PCR primer. For the allele-specific amplification, one of the mismatch primers and P2 were used. The expected size PCR products using $\mathrm{P} 1$ and $\mathrm{P} 2$, and $\mathrm{P}$ (mismatch) and $\mathrm{P} 2$ are 128 and $74 \mathrm{bp}$, respectively. The primary sequence of primers $\mathrm{P} 1$ and $\mathrm{P} 2$ are 5'-CCTGGTTTGGCAACCCCTGT-3' and 5'-ACTCGTCCACAAAATGGTTC$3^{\prime}$ respectively. this position. In addition to varying the number of mismatches from one to three (Table 1), we also varied the position of the allele-specific adenosine residue within the primer between the 3' ultimate or penultimate position. As shown in Figure 2, the allele-specific primers carrying a single mismatch had no effect on the overall PCR yield, amplifying the target sequence at a calculated efficiency of $70 \%$ per cycle during the exponential phase of DNA synthesis. On the other hand, primers carrying two or more consecutive mismatches at the $3^{\prime}$ end (Fig. 2A, lanes 3, 4, 5, 6, and B, lane 5) failed to generate any detectable amplification products during the first 30 cycles of PCR. Under the condition tested, extension efficiency $\left(Y_{\mathrm{o}}\right)$ for these primers containing two or more mismatches was less than 0.007 , indicating that less than 2100 copies of the $3 \times 10^{5}$ template copies were extended during the first cycle of PCR (Table 1; also see Materials and Methods). For the purpose of specifically amplifying only the transforming allele of the c-H-ras gene but not the wild-type allele, we therefore chose to use the double-mismatch primers that generate two mismatches and one mismatch at their $3^{\prime}$ terminus when hybridized to wild-type and transforming alleles, respectively.

For the G-to-A mutation at the 12th codon of the c-H-ras gene, there are 12 double-mismatch primers with the characteristic of having two mismatches with the wild-type allele and one mismatch with the transforming allele. Among the six double-mismatch primers tested ( $\mathrm{Ta}$ ble 1: PAA, PCA, PTA, PGAC, PGAT, PGAG), five permitted amplification of the mutant allele with a high degree of specificity, suggesting that for the G-to-A transition of the ras gene the nature of mismatches may not be crucial for the allele-specific amplification (Fig. 3, Table 1). A notable exception was the PGAG primer, which amplified the wildtype allele with two mismatched bases at the $3^{\prime}(\mathrm{AG} / \mathrm{CT})$ as efficiently as the transforming allele that had one base mismatch (A/C) (Fig. 3g, $Y_{\mathrm{O}(\mathrm{wt})}=Y_{\mathrm{O}(\mathrm{t})}=$ 0.7).

\section{Optimization of the PCR Conditions for the Allele-specific Amplification}

For the analysis of the various mismatch primers described above, we utilized a three-step Taq PCR which consisted of 


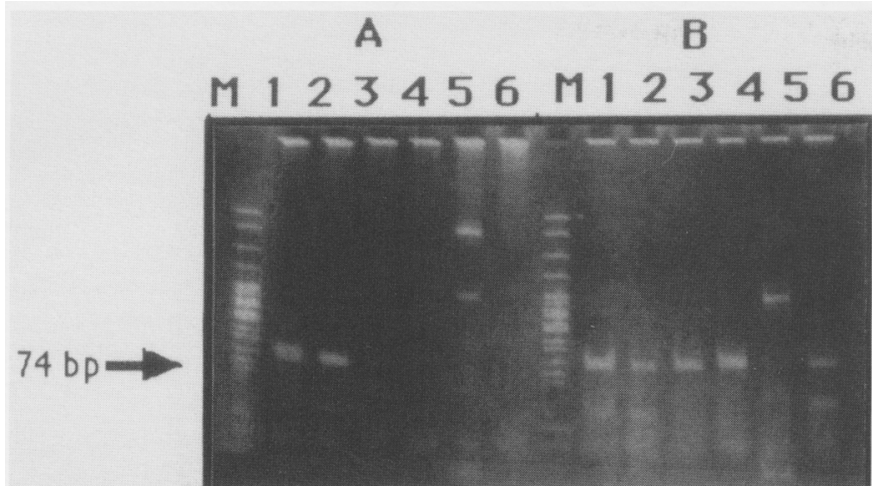

FIGURE 2 Specificity of mismatch primers. One-microgram aliquots of genomic DNA $\left(\sim 3 \times 10^{5}\right.$ copies of ras gene) from rat liver or NMU-induced rat mammary tumor carrying the 12th codon G-to-A alteration was subjected to 30 cycles of PCR using primers P2 and one of the mismatch primers (Fig. 1). Each cycle consisted of $94^{\circ} \mathrm{C}$ for $1 \mathrm{~min}, 55^{\circ} \mathrm{C}$ for $1 \mathrm{~min}$, and $72^{\circ} \mathrm{C}$ for $1 \mathrm{~min}$. Following the completion of mismatch PCR, one-tenth of the product was analyzed on a polyacrylamide gel. The arrow indicates the position of the 74-bp transforming allele-specific amplification band. Lane $M$ contained $250 \mathrm{ng}$ of pBR322 digested with MspI as molecular size marker. (A) Amplification products from wild-type rat genomic DNA. (B) Allele-specific PCR product from the rat mammary tumor genomic DNA. The mismatch primers tested are: (lane 1) PA-1: (lane 2) PA; (lane 3) PAA-1; (lane 4) PAA; (lane 5) PCAA; (lane 6) PG-AA.

$94^{\circ} \mathrm{C}$ for $1 \mathrm{~min}, 55^{\circ} \mathrm{C}$ for $1 \mathrm{~min}$, and $72^{\circ} \mathrm{C}$ for 1 min. Following 30 cycles of PCR under such conditions, no detectable amplification product was generated from wild-type DNA using the doublemismatch primer PAA (Fig. 2A, lanes 3 and 4). However, when an additional 15 cycles of amplification were carried out, about $10^{12}$ copies of the 74-bp fragment were generated from the wild-type DNA (data not shown). Assuming that the PCR was in the exponential phase of
DNA synthesis during the 45 cycles, the estimated efficiency of double-mismatch extension $\left(Y_{0}\right)$ is about 0.0002 , indicating that approximately 70 copies of PAA were extended from the $3 \times 10^{5}$ copies of wild-type DNA during the first cycle (Table 1; also see Materials and Methods). To reduce the extension from the double-mismatch primer even further, we first tried placing an additional third mismatch in the primer. This primer failed to amplify the transforming allele

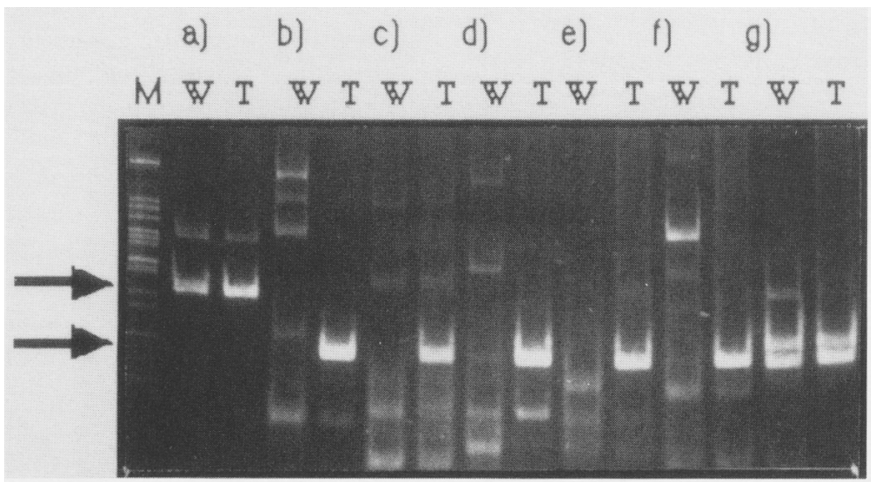

FIGURE 3 Specificity of double-mismatch primers. One-microgram aliquots of genomic DNA $\left(\sim 3 \times 10^{5}\right.$ copies of ras gene) from either rat liver (W) or a NMU-induced rat mammary tumor (T) carrying the 12th codon G-to-A alteration were subjected to 30 cycles of PCR using primers P2 and each of the six different double-mismatch primers (lanes $b-g$ ). Each cycle consisted of incubation at $94^{\circ} \mathrm{C}$ for $1 \mathrm{~min}, 55^{\circ} \mathrm{C}$ for $1 \mathrm{~min}$, and $72^{\circ} \mathrm{C}$ for $1 \mathrm{~min}$. Following the completion of mismatch PCR, one-tenth of the product is analyzed on a polyacrylamide gel. Lane $M$ contained 250 ng of pBR322 digested with Mspl as molecular size marker. The 74-bp band represents the mutant-specific amplification band and the 128-bp band is the control amplification product using P1 and P2 (Fig. 1). The primers tested are: (lane $a$ ) the control primer P1; (lane $b$ ) PAA; (lane c) PCA; (lane $d$ ) PTA; (lane e) PGAC; (lane f) PGAT; (lane g) PGAG.

(Fig. 2B, lane 5), and therefore could not be used for the purpose of selectively amplifying the mutant sequence.

Our next approach was to alter the PCR reaction conditions. First, we shortened the PCR cycle to a two-step reaction consisting of a template denaturation step and a primer annealing/extension step. We kept the first step constant at $94^{\circ} \mathrm{C}$ for $1 \mathrm{~min}$ and varied the second step. We tested temperatures ranging from $48^{\circ} \mathrm{C}$ to $57^{\circ} \mathrm{C}$, and the samples were incubated at the specified temperature for either $1 \mathrm{~min}$ or $5 \mathrm{sec}$ (Fig. 4). Under all the conditions tested, no detectable amplification product was generated from $1 \mu \mathrm{g}$ of wild-type DNA following 30 cycles of PCR, while all the mutant DNA samples were efficiently amplified. When 15 additional cycles of amplification were carried out, however, a difference in the overall amplification yield from the wild-type allele became apparent (Fig. 4). Surprisingly, the signal corresponding to the 74-bp transforming allele-specific fragment generated from wild-type DNA sample was minimal when the temperature was lowered to $50^{\circ} \mathrm{C}$ or $48^{\circ} \mathrm{C}$, a condition usually regarded as being less stringent/specific. Among the conditions tested, $94^{\circ} \mathrm{C}$ for 1 min followed by $50^{\circ} \mathrm{C}$ for $1 \mathrm{~min}$ generated the minimum amount of the specific 74-bp fragment from the wild-type DNA sample (Fig. 4).

\section{Reconstruction Experiment}

The limit of sensitivity the MAMA procedure was estimated by a reconstruction experiment. Approximately $3 \times 10^{6}$ copies of $(10 \mu \mathrm{g})$ of wild-type genomic DNA were mixed with $0,30,300$, and 3000 copies of transforming allele from tumor genomic DNA. Each mixture was subjected to the two-step PCR using PAA as the allele-specific primer. At the same time, 30, 300, and 3000 copies of transforming allele were amplified in the absence of wild-type DNA as a set of controls (Fig. 5a). Under the current reaction conditions, the two-step PCR using PAA as the allele-specific primer displayed a sensitivity of $10^{-4}$. The signal from $3 \times 10^{6}$ copies of the wild-type allele was stronger than that from 30 copies of the mutant allele alone (Fig. 5a), suggesting that the limit of sensitivity was due to the generation of the 74-bp PCR product from the vast excess of wild-type allele present. In an attempt to reduce the 


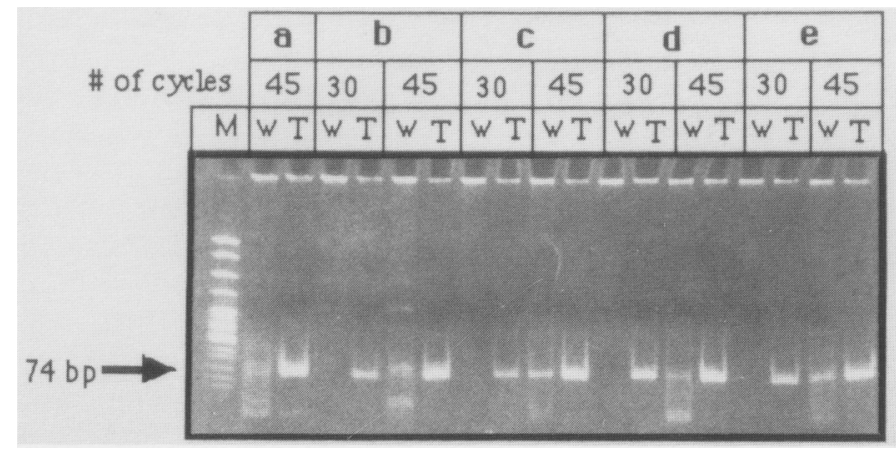

FIGURE 4 Effect of modifying PCR cycles on the specificity of PAA. One microgram $\left(\sim 3 \times 10^{5}\right.$ copies of ras gene) of genomic DNA from rat liver (W) or NMU-induced rat mammary tumor (T) with the 12th codon G-to-A alteration is subjected to two-step PCR using primers PAA and P2. Each reaction mixture was subjected to a different PCR procedure. (a) $94^{\circ} \mathrm{C}$ for $1 \mathrm{~min}$ and $48^{\circ} \mathrm{C}$ for $1 \mathrm{~min}$. (b) $94^{\circ} \mathrm{C}$ for $1 \mathrm{~min}$ and $50^{\circ} \mathrm{C}$ for $1 \mathrm{~min}$. (c) $94^{\circ} \mathrm{C}$ for $1 \mathrm{~min}$ and $55^{\circ} \mathrm{C}$ for $1 \mathrm{~min}$. (d) $94^{\circ} \mathrm{C}$ for $1 \mathrm{~min}$ and $55^{\circ} \mathrm{C}$ for $5 \mathrm{sec}$. (e) $94^{\circ} \mathrm{C}$ for $1 \mathrm{~min}$ and $57^{\circ} \mathrm{C}$ for $1 \mathrm{~min}$. One-tenth of the reaction time mixture was taken following 30 and 45 cycles of PCR and analyzed on a polyacrylamide gel. The arrow indicates the 74-bp transforming allele-specific amplification product. Lane $M$ contained $250 \mathrm{ng}$ of pBR322 digested with MspI as molecular size marker.

overall yield from the wild-type DNA, we altered the solvent composition of the PCR reaction mixture by adding different amounts of glycerol.

Identical reaction mixtures were prepared with the addition of either $5 \%$ or $10 \%(\mathrm{vol} / \mathrm{vol})$ of glycerol. These reaction mixtures were subjected to 35 cycles of two-step PCR protocol (Fig. 5b,c). As shown in Figure 5, the addition of glycerol enhances the specificity of the PCR reaction by reducing the amplification of the wild-type sequence with the allelespecific primer. As the concentration of glycerol increased, the signal generated from $3 \times 10^{6}$ copies of wild-type DNA decreased. With the addition of $10 \%$ glycerol in the PCR mixture, virtually no signal was detected from the sample containing $3 \times 10^{6}$ copies of wild-type allele alone while the identical mixture containing 30 molecules of transforming ras allele generated a clear signal, indicating that fewer than 30 molecules of PAA were extended in the presence of $3 \times 10^{6}$ copies wild-type allele during the first cycle of PCR (Fig. 5c).

\section{DISCUSSION}

In this study, we optimized the allelespecific PCR procedure with regard to its sensitivity utilizing one of the transforming alleles of rat c-H-ras gene (Gto-A transition at the 12th codon) as a model system. By exploring double-mismatch primers, altering the duration and the temperature of the primer anneal- ing/extension step in PCR cycle, and modifying the solvent composition of the reaction mixture by adding glycerol, we could reproducibly carry out quantitative measurement of the transforming allele that was present at a frequency of 1 in 100,000 . This improvement on the sensitivity of allele-specific amplification would greatly expand the general application of the procedure whose primary utility thus far had been limited to the detection of inherited genetic variations in human.

Ehlen and Dubeau have reported an assay for detection of GC-to-TA transversion at the 12th codon of human c-H-ras gene utilizing allele-specific mismatch primers. ${ }^{(5)}$ These authors claimed a sensitivity of $10^{-7}$ based on a reconstruction experiment utilizing $1 \mu \mathrm{g}$ of genomic DNA. However, $1 \mu \mathrm{g}$ of mammalian genomic DNA contains only $3 \times 10^{5}$ copies of an autosomal gene, and therefore, it would be impossible to have detected a signal representing lower than about $10^{-5}$. This apparent discrepancy may account for the fact that their approach has not been widely applied. On the other hand, the MAMA for the 12th codon G-to-A transition of the rat c-H-ras gene has already been found sufficient for measurement of c-H-ras mutations in untreated rats at frequency as low as $10^{-5}$ (R.S.C., W.G.T., and H.Z., in prep.). Moreover, an MNNG-induced mutational hotspot (Dr. Alexandra Kat, pers. comm.) and an $\mathrm{X}$-ray-induced frameshift mutational

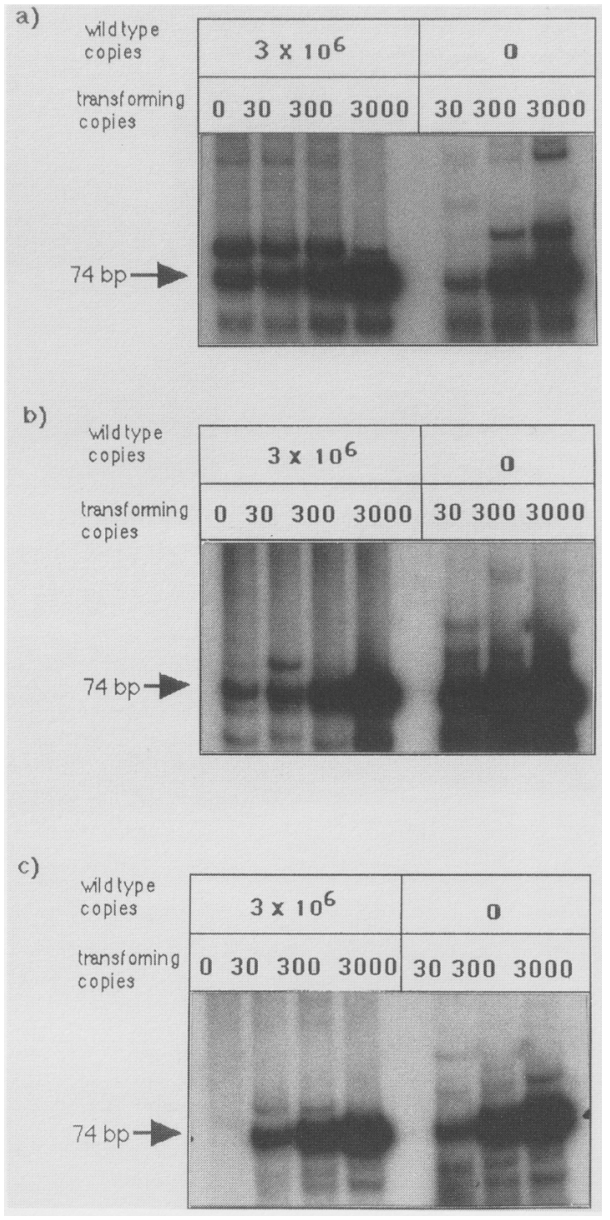

FIGURE 5 Effect of glycerol on the sensitivity of mismatch amplification mutation assay (MAMA). From the left to right, $10 \mu \mathrm{g}$ $\left(\sim 3 \times 10^{6}\right.$ copies of the ras gene) of genomic DNA from rat liver was mixed with various amounts of tumor genomic DNA representing approximately 30,300 , and 3000 copies of the mutant sequences. The next three lanes contain only the tumor genomic DNA. Samples were subjected to 35 cycles of two-step PCR consisting of $1 \mathrm{~min}$ of incubation at $94^{\circ} \mathrm{C}$ followed by $1 \mathrm{~min}$ of incubation at $50^{\circ} \mathrm{C}$. The arrows indicate the position of 74-bp transforming allele-specific amplification band. Reaction mixture contained either $0 \%(a), 5 \%$ (b), or $10 \%(c)$ glycerol ( $\mathrm{vol} / \mathrm{vol})$. For the reconstruction experiment, autoradiogram was utilized to visualize amplification products because 35 cycles of amplification from 30 copies of template at an efficiency of $70 \%$ per cycle would yield approximately $3 \times 10^{9} \mathrm{~mol}$ ecules of the 74-bp fragment, which is under the limit of detection by ethidium bromide staining.

hotspot (Dr. Rich Okinaka, pers. comm.) in human cells have also been successfully measured using our approach. Nevertheless, it should be pointed out that 
 \\ Downloaded from genome.cship.org on April 26, 2023 - Published by Cold Spring Harbor Laboratory Press}

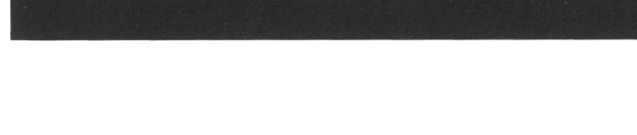

whether or not the specific parameters optimized for the 12th codon G-to-A transition of the $\mathrm{c}-\mathrm{H}$-ras gene will be as effective for other sequences remains to be determined. Because numerous studies indicate that the specificity of allelespecific PCR is influenced by both the nature of mismatches and the sequence to be amplified, ${ }^{(1,12)}$ it is possible that an optimal MAMA condition may need to be determined on a sequence-by-sequence basis.

The development of allele-specific PCR utilizing $3^{\prime}$ terminal mismatch(es) was based on observations that correctly paired bases were much more readily extended by DNA polymerases than mispaired bases. ${ }^{(19,20)}$ By measuring the extension efficiencies of different mismatch primers hybridized to M13 template, investigators reported that perfectly matched bases were $10^{2}-10^{6}$ times more efficiently extended than mismatched bases, depending on DNA polymerases and the nature of mismatches. ${ }^{(19,20)}$ For the 12th codon G-to-A transition of the c-H-ras gene, we find that primers containing one mismatch at the ultimate or penultimate position of the 3 ' end of the primer extend as efficiently as a perfect match primer with a calculated efficieny of $70 \%$ per cycle. When an additional mismatch was placed, about 100-fold reduction (from 0.7 to 0.007 , Table 1 ) in the efficiency of extension was observed. Under the condition optimized for the transforming allele-specific amplification, the probability of a double-mismatch primer extension was less than $10^{-5}$ (Fig. 5; see Results). Undoubtedly, this probability determines the limit of sensitivity, and any modification of the procedure that results in the reduction of this probability would improve the sensitivity.

Numerous studies on fidelity of in vitro DNA polymerization and mispaired base extension have demonstrated that the extent of such discrimination by DNA polymerases is influenced by the number and nature of mismatches, ${ }^{(1,12)}$ and many factors in the reaction mixture such as $\mathrm{pH}^{(12,21,23)}$ the concentration of primers, ${ }^{(8)}$ dNTPs ${ }^{(12,21)}$ and magnesium ions $\left(\mathrm{mg}^{2+}\right) .{ }^{(12,23,24)}$ To explore the possibility that altering these parameters would further enhance the sensitivity of the MAMA by lowering the likelihood of the double-mismatch extension, we modified the reaction buffer by varying the $\mathrm{pH}$ between 8.4 (original condition) and 5.0, the concentrations of $\mathrm{MgCl}_{2}$ between $2.25 \mathrm{~mm}$ (original condition) and $0.1 \mathrm{mM}$, and the concentrations of dNTPs between $37 \mu \mathrm{M}$ (original condition) and $3.7 \mu \mathrm{M}$. We chose the lower values for these three variables from the results of previous studies indicating that higher fidelity of in vitro polymerization is achieved when these values are lowered. ${ }^{(8,23,24)}$ Under the various PCR conditions tested, we observed that the overall efficiency of amplification for both the wild-type allele and the transforming allele decreased. The extent of the reduction in the efficiencies was comparable between the two alleles, and no significant enhancement on the sensitivity was observed (data not shown). It should also be noted that no detectable amount of amplification product was generated from either the wild-type allele or the transforming allele when $\mathrm{pH}$ was lower than 7.0 or the concentrations of $\mathrm{MgCl}_{2}$ were below $0.5 \mathrm{~mm}$.

The mutation we have utilized as a model system in this study, the G-to-A transition at the second nucleotide of the 12th codon of ras gene, is one of the most frequently observed alterations in many types of tumors of both human and animal origins. ${ }^{(25)}$ Consequently, tumors are screened routinely for the presence of this mutation. Utilizing MAMA for detecting the transforming ras allele in tumors would provide many advantages over other molecular techniques currently used, such as RFLP and differential oligonucleotide hybridization. In addition to its simplicity, speed, and sensitivity, the MAMA generates quantitative output (Fig. 5c), providing an opportunity to measure the actual fraction of the sample DNA carrying the 12 th codon alteration. Assuming that tumors are clonal in origin, such analysis, in turn, would make it feasible to assess the timing of ras gene activation. In addition, with its present ability to detect 30 copies of transforming ras alleles present amongst $3 \times 10^{6}$ copies of wildtype allele, MAMA may be utilized to analyze quantitatively the molecular events that occur during the earlier stages of chemically induced tumorigenesis in a target organ where the number of cells with a mutated oncogene is believed to be very small. Finally, it should be pointed out that because there is a restriction enzyme (MnlI) that selectively cleaves the wild-type c-H-ras allele, the current sensitivity of the MAMA for the G-to-A transition of the c-H-ras gene can be further enhanced by a factor of 10 or more by digesting genomic DNA samples prior to MAMA.

\section{ACKNOWLEDGMENTS}

This work was supported by grants from the U.S. Department of Energy (DEFG02-86ER60448), the National Institute of Environmental Health Sciences, Biomarkers Program Project Grant (E505622), Soot Program Project Grant (E501640), and GenTox Program Project Grant (E503926).

\section{REFERENCES}

1. Newton, C.R., A. Graham, L.E. Heptinstall, S.J. Powell, C. Summers, N. Kalsheker, J.C. Smith, and A.F. Markham. 1989. Analysis of any point mutation in DNA. The amplification refractory mutation system. Nucleic Acids Res 17: 25032516.

2. Nichols, W.C., J.J. Liepnieks, V.A. McKusick, and M.D. Benson. 1989. Direct sequencing of the gene for Maryland/ German familial amyloidotic polyneuropathy type II and genotyping by allelespecific enzymatic amplification. Genomics 5: 535-540.

3. Okayama, H., D.T. Curiel, M.L. Brantly, M.D. Holmes, and R.G. Crystal. 1989. Rapid, nonradioactive detection of mutations in the human genome by allele-specific amplification. J. Lab. Clin. Med. 114: 105-113.

4. Wu, D.Y., L. Ugozzoli, B.K. Pal, and R.B. Wallace. 1989. Allele-specific enzymatic amplification of $\beta$-globin genomic DNA for diagnosis of sickle cell anemia. Proc. Natl. Acad. Sci. 86: 2757-2760.

5. Ehlen, T. and L.Dubeau. 1989. Detection of ras point mutations by polymerase chain reaction using mutation-specific, inosine-containing oligonucleotide primers. Biochem. Biophys. Res. Commun. 160: $441-447$.

6. Kan, Y.W. and A.M. Dozy. 1978. Antenatal diagnosis of sickle-cell anemia by DNA analysis of amniotic-fluid cells. Lancet: 910-912.

7. Verlaan-dc Vries, M., M.E. Bogaard, H. van de Elst, J.H. van Bloom, A.J. van der Eb, and J.L. Bos. 1986. A dot-blot screening procedure for mutated ras oncogenes using synthetic oligonucleotides. Gene 50: $313-320$.

8. Sarkar, G., J. Cassady, C. Bottema, and S. Sommer. 1990. Characterization of polymerase chain reaction amplification of specific alleles. Anal. Biochem. 186: 64-68.

9. Saiki, R.K., D.H. Gelfand, S. Stoffel, S.J. 
Scharf, R. Higuchi, G.T. Horn, K.B. Mullis, and H.A. Erlich. 1988. Primer-directed enzymatic amplification of DNA with a thermostable DNA polymerase. Science 239: 487-491.

10. Kahn, S.M., W. Jiang, T.A. Culbertson, B. Weinstein, G.M. Williams, N. Tomita, and Z. Ronai. 1991. Rapid and sensitive nonradioactive detection of mutant K-ras genes via "enriched" PCR amplification. Oncogene 6: 1079-1083.

11. Kumar, R. and M. Barbacid. 1988. Oncogene detection at the single cell level. Oncogene 3: 647-651.

12. Kwok, S., D.E. Kellogg, N. McKinney, D. Spasic, L. Goda, and J.J. Sninsky. 1990. Effects of primer-template mismatches on the polymerase chain reaction: Human immunodeficiency virus type 1 model studies. Nucleic Acids Res. 18: 999-1005.

13. Kleppe, K., E. Ohtsuka, R. Kleppe, I. Molineux, and H.G. Khorana. 1971. Studies on polynucleotides. XCVI. Repair replications of short synthetic DNA's as catalyzed by DNA polymerases. J. Mol. Biol. 56: 341-361.

14. Saiki, R.K., S. Scharf, F. Faloona, K.B. Mullis, G.T. Horn, H.A. Erlich, and A. Arnheim. 1985. Enzymatic amplification of $\beta$-globin sequences and restriction site analysis for diagnosis of sickle cell anemia. Science 230: 1350-1354.

15. Sambrook, J., E.F. Fritsch, and T. Maniatis. 1989. Molecular cloning: A laboratory manual, 2nd ed. Cold Spring Harbor Laboratory Press, Cold Spring Harbor, New York.

16. Fischer, S.G. and L.S. Lerman. 1983. DNA fragments differing by single base-pair substitutions are separated in denaturing gradient gels: Correspondence with melting theory. Proc. Natl. Acad. Sci. 80: 15791583.

17. Sheffield, V.C., D.R. Cox, L.S. Lerman, and R.M. Myer. 1989. Attachment of a 40base pair $\mathrm{G}+\mathrm{C}$ rich sequence (GC-clamp) to genomic DNA fragments by the polymerase chain reaction results in improved detection of a single-base changes. Proc. Natl. Acad. Sci. 86: 232-236.

18. According to ref. 15 , a diploid mammalian genome contains approximately $6 \times 10^{9} \mathrm{bp}$, which is equivalent to $6.8 \times 10^{-12}$ grams. Thus, $1 \mu \mathrm{g}$ of mammalian genomic DNA represents about $1.47 \times 10^{5}$ cells or $2.94 \times 10^{5}$ autosomal gene copies. We used $1.5 \times 10^{5}$ cells or $3 \times 10^{5}$ autosomal gene copies per $1 \mu \mathrm{g}$ of genomic DNA throughout this paper.

19. Mendelman, L.V., J. Petruska, and M.F. Goodman. 1990. Mispair extension kinetics. J. Biol. Chem. 265: 2338-2346.

20. Petruska, J., M.F. Goodman, M.S. Boosalis, L.C. Sowers, C. Cheong, and I. Tinoco. 1988. Comparison between DNA melting thermodynamics and DNA polymerase fidelity. Proc. Natl. Acad. Sci. 85: 62526256.
21. Eckert, K.A. and T.A. Kunkel. 1990. High fidelity DNA synthesis by the Thermus aquaticus DNA polymerase. Nucleic Acids Res. 18: 3739-3743.

22. Keohavong, P. and W.G. Thilly. 1989. Fidelity of DNA polymerases in DNA amplification. Proc. Natl. Acad. Sci. 86: 92539257.

23. Ling, L.L., P. Keohavong, C. Dias, and W.G. Thilly. 1991. Optimization of the polymerase chain reaction with regard to fidelity: Modified T7, Taq, and Vent DNA polymerases. PCR Methods Applic. 1: 6369.

24. Ecket, K.A. and T.A. Kunkel. 1991. DNA polymerase fidelity and the polymerase chain reaction. PCR Methods Applic. 1: 17 24.

25. Barbacid, M. 1987. ras genes. Annu. Rev. Biochem. 56: 779-827.

Received January 15, 1992; accepted in revised form April 20, 1992. 


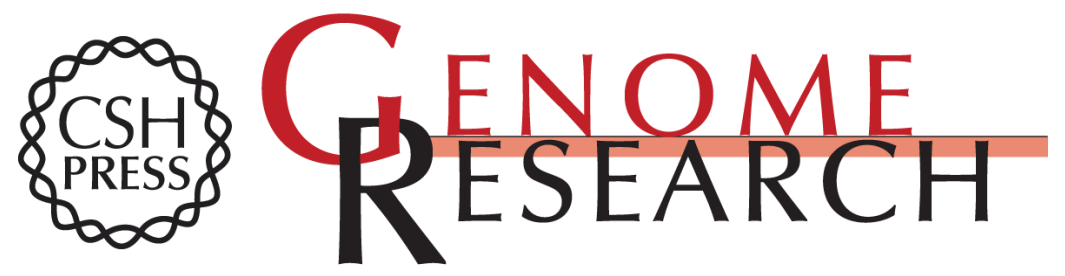

\section{Mismatch amplification mutation assay (MAMA): application to the c-H-ras gene.}

R S Cha, H Zarbl, P Keohavong, et al.

Genome Res. 1992 2: 14-20

Access the most recent version at doi:10.1101/gr.2.1.14

References This article cites 22 articles, 7 of which can be accessed free at:

http://genome.cshlp.org/content/2/1/14.full.html\#ref-list-1

\section{License}

Email Alerting Receive free email alerts when new articles cite this article - sign up in the box at the Service top right corner of the article or click here.

\section{Affordable, Accurate Sequencing.}

To subscribe to Genome Research go to: https://genome.cshlp.org/subscriptions 